\title{
Analysis and Visualisation of Research Trends in Nano Material: A General Review
}

\author{
Ranvijay Kumar ${ }^{1}$ \\ ${ }^{1}$ Department of Mechanical Engineering Chandigarh University, Gharuan, Mohali, Punjab, 140413
}

Article History: Received: 11 January 2021; Accepted: 27 February 2021; Published online: 5 April 2021

Abstract: Technically, the material possessing a minimum, one external dimension measuring 1-100nm is called Nanomaterial, and cannot be seen by the naked eye. The bibliometric analysis had been conducted to understand the active authors, organizations, journals, and countries involved in the research domain of "Nanomaterial"[1], [2]. All published articles related to "Nanomaterial" from "Scopus", were analyzed using the VOS viewer to develop analysis tables and visualization maps. This article had set the objective to consolidate the scientific literature regarding the "Nanomaterial"and also to find out the trends related to the same.The most active journals in this research domain were Construction and Building Materials and Composites Science and Technology. The most active countries were China and the United States of America. The leading organizations engaged in the research regarding Nanomaterial was the Chinese Academy of Sciences, the North Eastern University of China, and the Ministry of Education of China.The most active authors who had made valuable contributions related to Nanomaterial were Wang Y. and Yang $\mathrm{H}$.

Keywords:Nanomaterial,Bibliometric analysis, VOS viewer

\section{Introduction}

The material possessing minimum, one external dimension measuring 1-100nm is called Nano material[3][5]. Most of the Nanomaterials are too small and cannot be seen by the naked eye. Nanomaterials are being used in numerous fields like chemicals, pharmaceutical sector, textile, cement; ${ }^{3}$ energy, transportation, electronics, and bioengineering. The Nanomaterials are extremely useful due to their smaller size and versatility; high catalytic activity and high solubility features[6]. However, the major concerns of Nanomaterials are their effect on health and knowledge gaps. There is numerous definition for Nanomaterial and "Material with any external dimension in the Nanoscale (Size range 1-100nm) or having an internal structure or external structure in Nanoscale"- ISO 2015. Similarly according to the definition of European Commission 2011 for Nanomaterial, "natural, incidental or manufactured material containing particles, in an unbound state or as an aggregate or as an agglomerate and where, for $50 \%$ or more of the particles in the number size distribution, one or more external dimensions is in the size range $1 \mathrm{~nm}-100 \mathrm{~nm}$."[7]-[9]. Nanomaterials can be generally of three types of origin, a) Nanomaterials with natural origin (Example: Volcanic ash) b) by-products of combustion process (Example: Diesel engines) c) engineered Nanomaterials for specific purposes.

1.1 Research Objectives

a) To consolidate the literature regarding the Nanomaterial

b) To find out the trends related to research in the Nanomaterial

The following research questions are framed for conducting bibliometric analysis systematically.

1.2 Research Questions

a) Who are the active researchers working on the Nanomaterial?

b) Which are the main organizations and countries working on Nanomaterial?

c) Which are the main journals related to Nanomaterial?

\subsection{Significance of this research}

The nanomaterialis an important research niche in material engineering. This article points out the need for future research regarding Nanotechnology andNanomaterial. This bibliometric analysis will be a useful platform for future researchers by realizing the top researchers, organizations, and countries involved in research regardingNanomaterial. This bibliometric article is arranged in four sections. The first section is the introduction, followed by the discussion of the methodology by which the research was conducted. The third section deals with results and discussion. The fourth section deals with the conclusion.

\section{Research Methodology}

Scopus files had been used for this article. For the article selection, the Boolean used was TITLE ("Nanomaterial") on 03/01/2020. All the tables in this paper were created by using Microsoft Excel and VOS Viewer. Grammarly was used for spelling and grammar checks. Mendeley was used for article review and citation.This paper had been inspired by bibliometric analysis in its presentation style, analysis, and methodology from the works. ${ }^{7-11}$

\section{Results and discussion}

3.1 Results

This first round of search produced an outcome of 1015 documents, intenlanguages, out of which 837 documents were in English. The classification of document categories is shown in Figure 1. For improving the 
quality of the analysis, we had selected only the peer-reviewed articles and all other documents had not been considered. Thus after using filters "Article"and "English" the second round search produced an outcome of 395 English articles (both open access and others) andhad been used to conduct bibliometric analysis and visualization using VOS Viewer. The English research articles in this domain since 1995 had been shown in Figure 2.

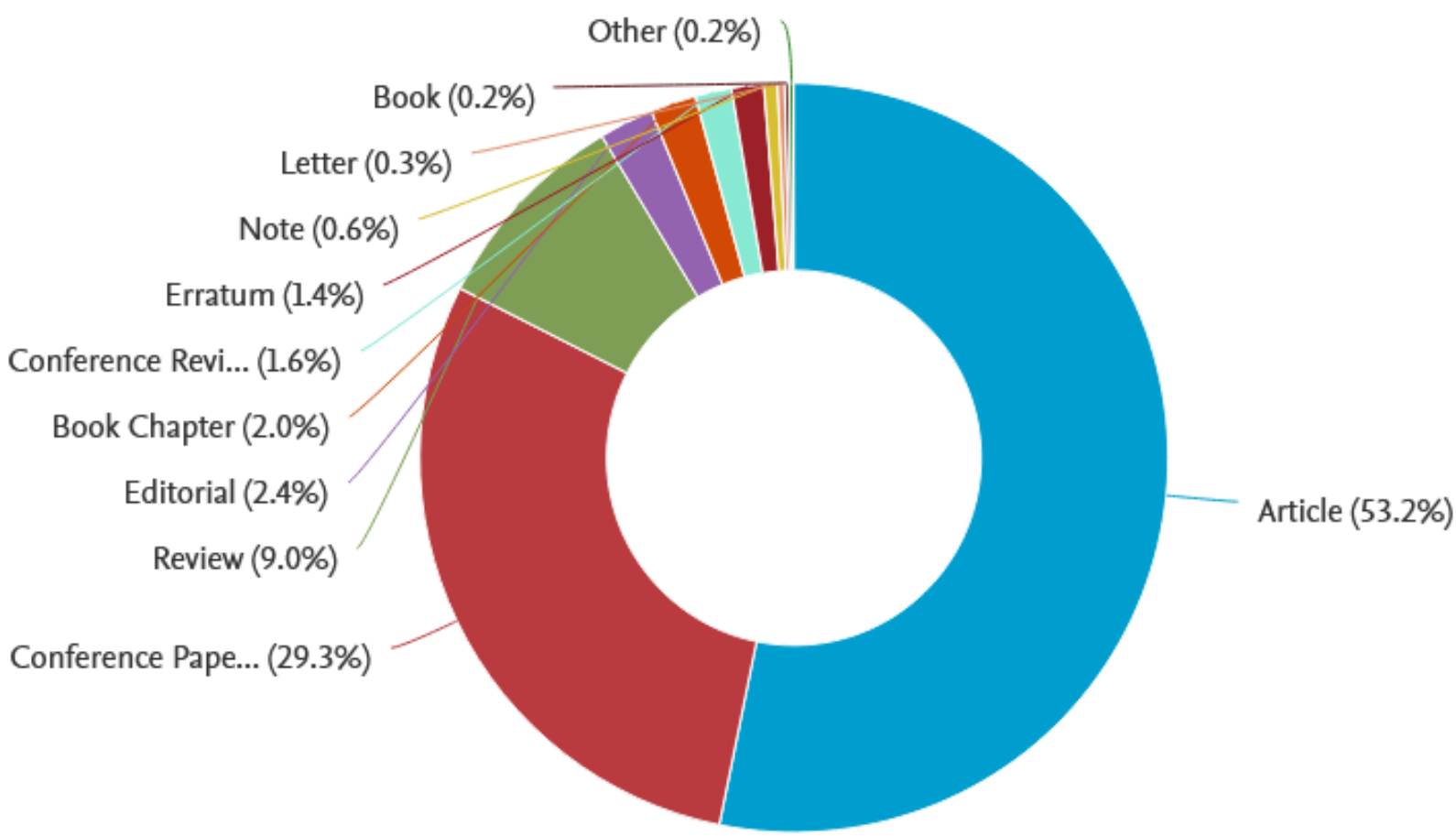

Figure 1: Classification of the documents on "Nanomaterial", Source: www.scopus.com 50

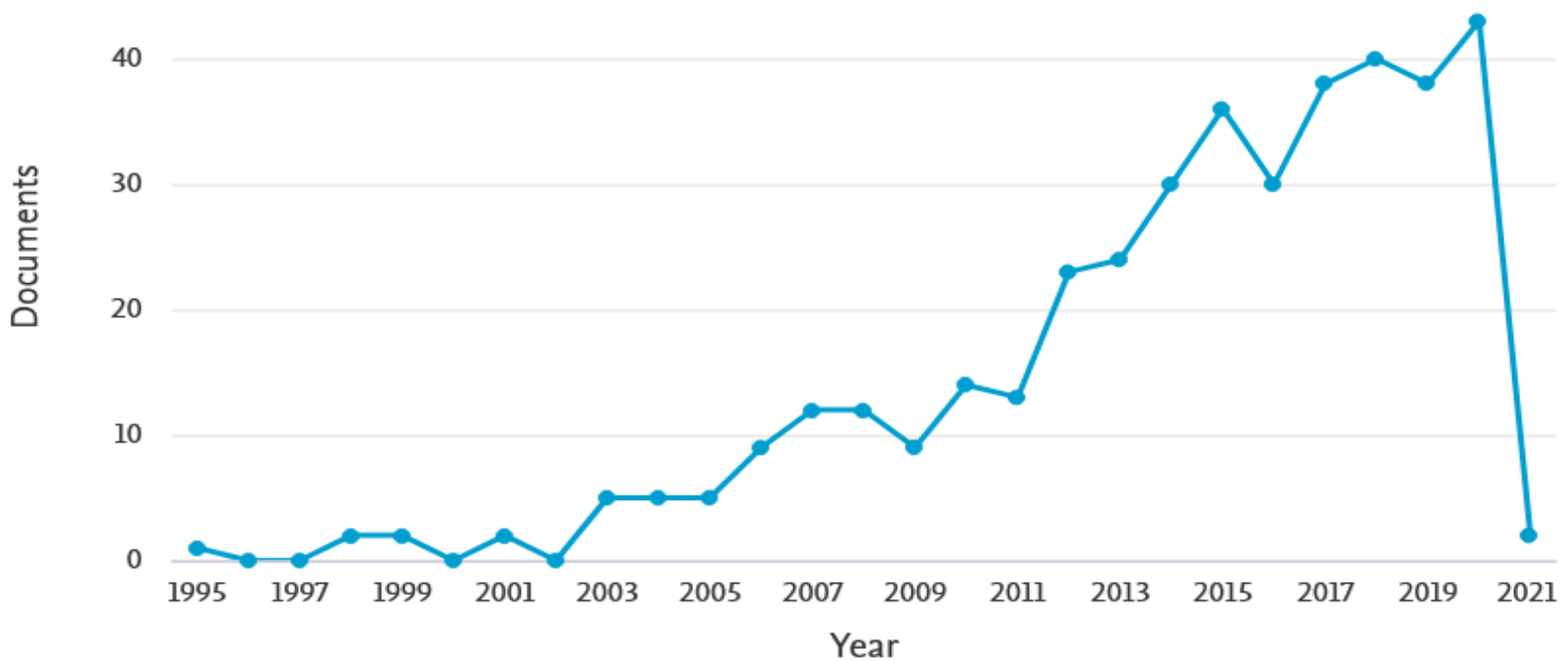

Figure 2: Period wise publication of articles, Source: WWW.scopus.com

Co-authorship analysis of top authors had been shown in figure 3. For a better presentation of the analysis, the parameters used were the minimum number of documents of an author as fourand the minimum number of citations of authors as one. This combination plotted the map of 30 authors, in 10 clusters. The overlay visualization map of co-authorship analysis plotted in Figure 3, points out the major researchers with their strong co-authorship linkages and clusters involved. 


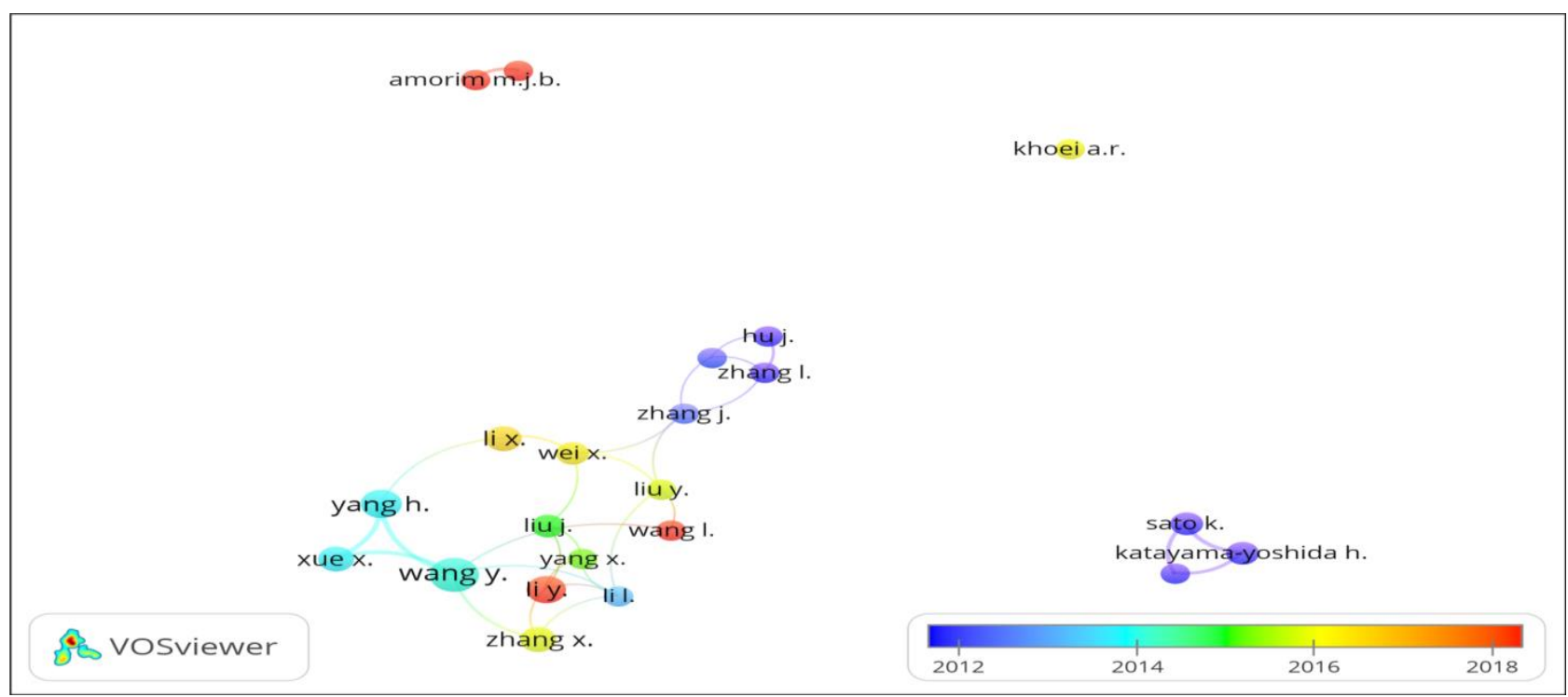

Figure 3: Co-authorship analysis on basis of authors

The citation analysis of top authors had been shown in table 1, along with co-authorship links.For the citation analysis, the parameters used werethe minimum number of documents of an author as one and the minimum citations of an author as one.

Table 1: Highlights of most active authors

\begin{tabular}{|c|c|c|c|c|c|}
\hline Description & Authors & $\begin{array}{l}\text { Documen } \\
\text { ts }\end{array}$ & $\begin{array}{l}\text { Citatio } \\
\text { ns }\end{array}$ & $\begin{array}{l}\text { Average } \\
\text { citations per } \\
\text { documents }\end{array}$ & $\begin{array}{l}\text { Link } \\
\text { strength }\end{array}$ \\
\hline $\begin{array}{l}\text { Authors with the } \\
\text { highest publication co- } \\
\text { authorship links }\end{array}$ & Wang Y. & 11 & 143 & 13 & 20 \\
\hline $\begin{array}{l}\text { Authors with the } \\
\text { highest citation }\end{array}$ & Yang H. & 8 & 223 & 28 & 14 \\
\hline
\end{tabular}

In Co-occurrence analysis, we had used all keyword analyses, by keeping the minimum number of occurrences of a keyword as 15. This combination plotted the map of 21thresholds, in threeclusters. The overlay visualization of co-occurrence analysis of keywords has been shown in Figure 4.

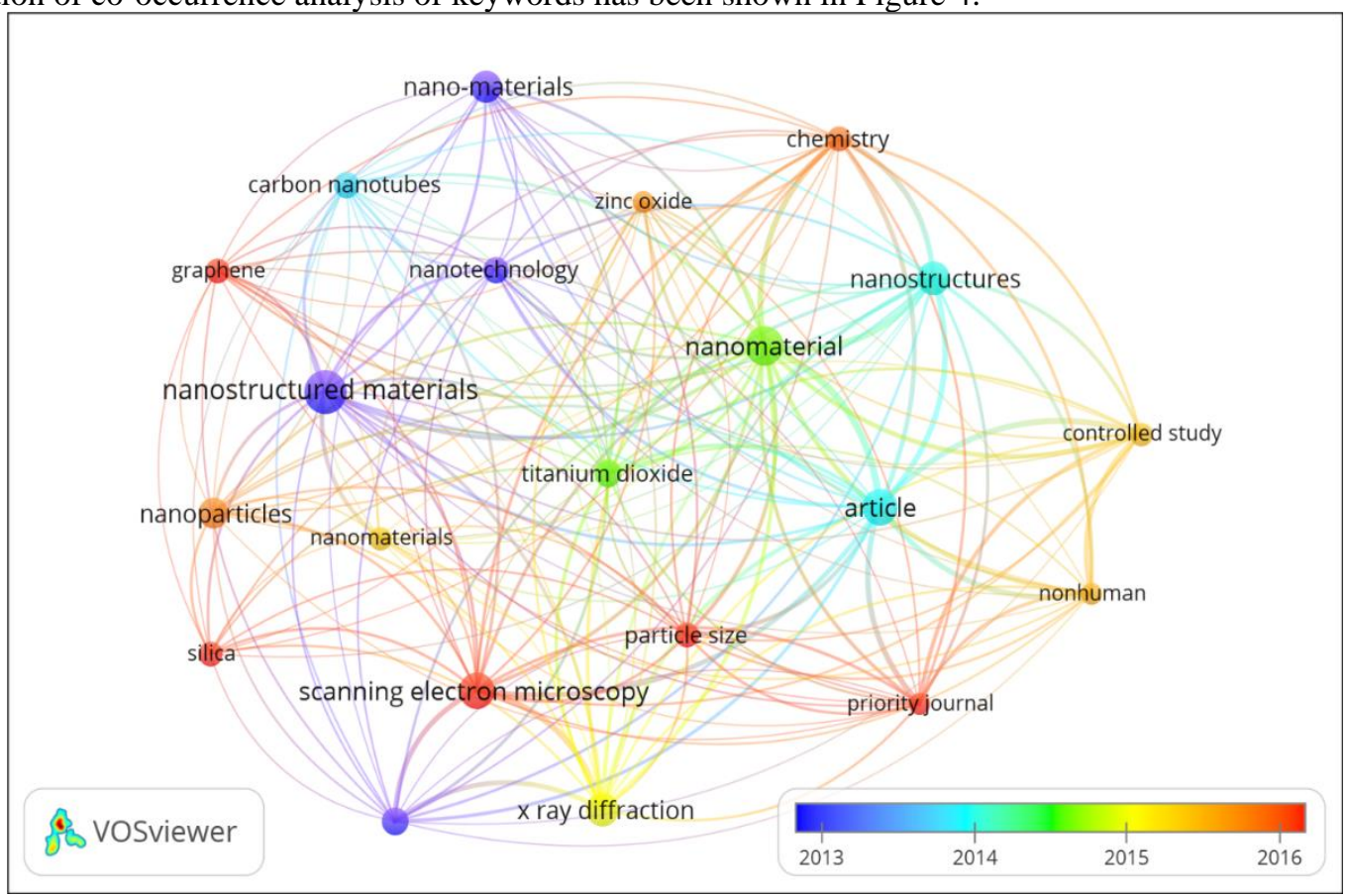

Figure 4: Co-occurrence analysis on basis of all keywords 
The leadingorganizations engaged in research on "Nanomaterial" had been found out by the volume of publications and citation analysis, the parameters used are the minimum number of documents of an organization as one and the minimum number of citations of organizations as one. This combination plotted the map of 736organizations, in 300clusters.

The leading organization in the research regarding "Nanomaterial", with the highest number of publications and citations, were the Chinese Academy of Sciences, North Eastern University of China, and Ministry of Education of China (Refer to table 2).

Table 2: Highlights of the most active organization

\begin{tabular}{|c|c|c|c|c|}
\hline Organizations & Country & Documents & Citatio & $\begin{array}{c}\text { Average } \\
\text { Citations } \\
\text { document }\end{array}$ \\
\hline per \\
Chinese Academy of Sciences & China & 14 & 164 & 11.7 \\
\hline Ministry of Education & China & 13 & 160 & 12.3 \\
\hline $\begin{array}{l}\text { North Eastern University of } \\
\text { China }\end{array}$ & China & 08 & 223 & 28 \\
\hline
\end{tabular}

Co-authorship analysis of the countries engaged in the research on "Nanomaterial" had been shown in Figure 5. For a better presentation of the analysis, the parameters used were the minimum number of documents of an author as five and the minimum number of citations of authors as one. This combination plotted the map of 26 countries,5clusters. The overlay visualization map of co-authorship analysis plotted in Figure 5, points out the main countries with their strong co-authorship linkages and clusters involved.

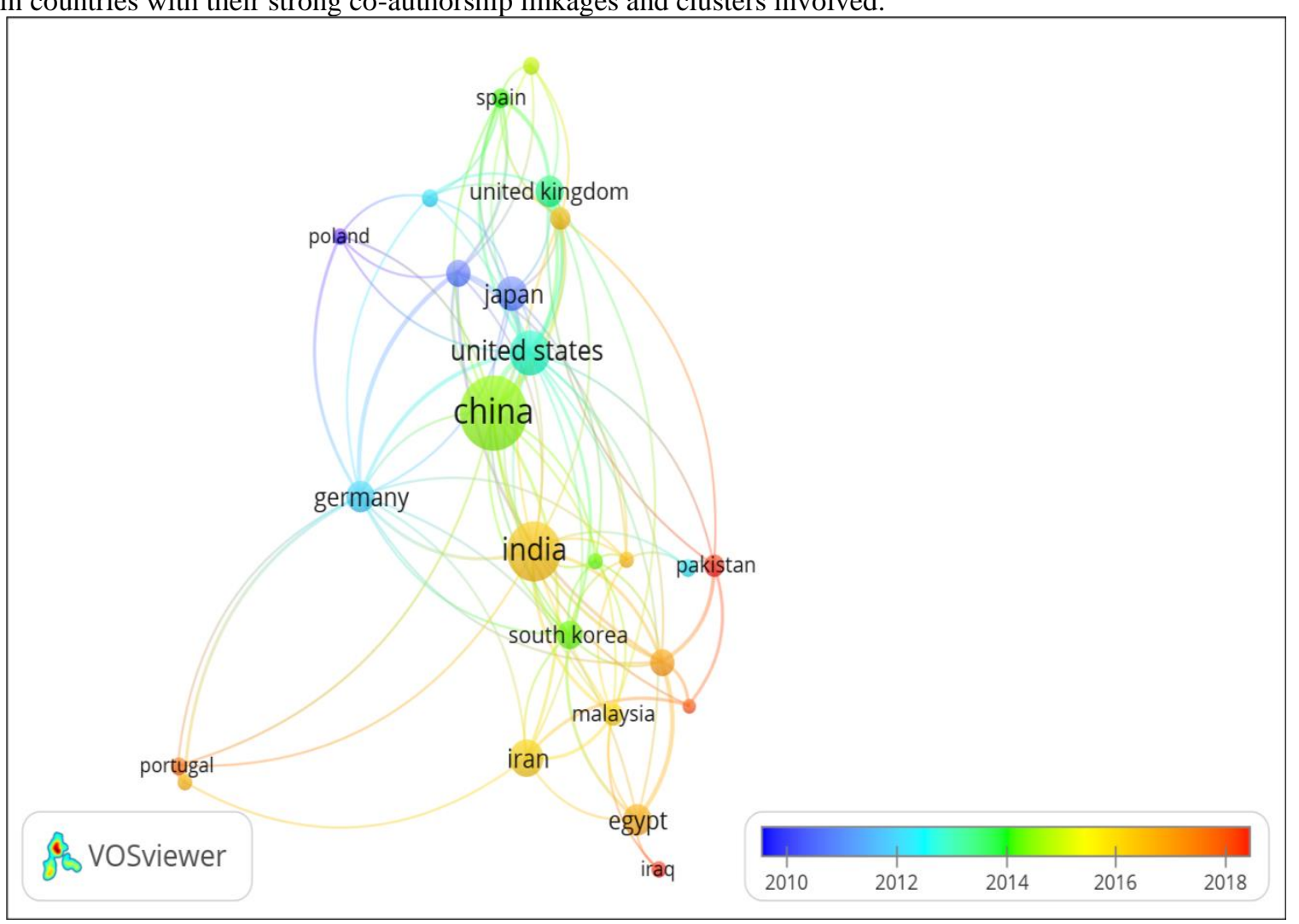

Figure 5: Co-authorship analysis on basis of countries

The citation analysis of top countries had been shown in table 3, along with co-authorship links. For the citation analysis, the parameters used were the minimum number of documents of acountry as one and the minimum citations of the country as one.

Table 3: Highlights of Active Countries

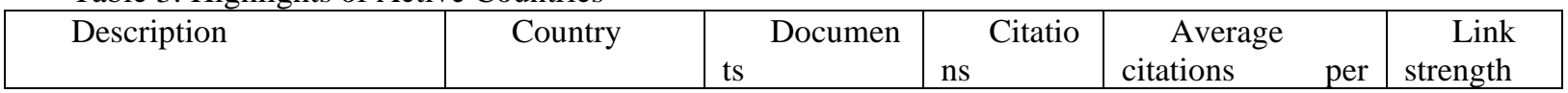




\begin{tabular}{|c|c|c|c|c|c|}
\hline & & & & documents & \\
\hline \multirow{2}{*}{$\begin{array}{l}\text { The country with the } \\
\text { highest publication, citation, } \\
\text { and co-authorship links }\end{array}$} & China & 108 & 1395 & 12.8 & 33 \\
\hline & $\begin{array}{l}\quad \text { United } \\
\text { States of } \\
\text { America }\end{array}$ & 40 & 1042 & 26.05 & 31 \\
\hline
\end{tabular}

The most active countries in this research domain were China andthe United States of America with the highest number ofpublications, citations, and co-authorship links.

Link analysis and citation analysis were used to identify the most active journal in this research domain. We have taken the parameters of the minimum number of documents of a journal as one and the minimum number of citations of a journal as one for the link analysis and citation analysis. Highlights of the most active and relevant journals related to the "Nanomaterial"are shown in table 4. Table 4shows the journal activity of this research domain through parameters of publication volume, citations, and co-authorship linkages. Construction and Building Materials and Composites Science and Technologywere the most active journal with the highest publications, citations, and co-authorship links.

Table 4: Analysis of journal activity

\begin{tabular}{|c|c|c|c|c|c|}
\hline Description & Journal details & ts & ns & \begin{tabular}{l}
\multicolumn{1}{c}{ Average } \\
citations per \\
documents
\end{tabular} & $\begin{array}{l}\text { Link } \\
\text { strength }\end{array}$ \\
\hline $\begin{array}{c}\text { Journal with the } \\
\text { highest publications }\end{array}$ & $\begin{array}{l}\text { Construction and } \\
\text { Building Materials }\end{array}$ & 09 & 208 & 13.1 & 0 \\
\hline $\begin{array}{ll}\text { Journal } & \text { with } \\
\text { thehighest citation } & \end{array}$ & $\begin{array}{l}\text { Composites } \\
\text { Science and } \\
\text { Technology }\end{array}$ & 03 & 249 & 83 & 0 \\
\hline
\end{tabular}

From the above discussion regarding the bibliometric patterns in the research regarding the Nanomaterial,this research had observed a gradual increase in research interest regarding the Nanomaterial from the starting of the millennium and the momentum is going on positively. This points out the relevance and potential of this research domain (Refer to Figure 2). The most active author in this research domainis Wang Y. and Yang H.with the highest publication, citations, and co-authorship links (Refer to table 1).The overlay analysis of top countries researching Nanomaterialindicates that the China and United States of Americawere the leading country in research regarding Nanomaterialwith the highest publications, citations, and co-authorship links(Refer to figure 5). The top journals of this research domain were identified as Construction and Building Materials and Composites Science and Technology. Fromthese wide sources of information, researchers can focus on top journals where they can identify the most relevant and highly cited articles regarding Nanomaterial.

\section{Conclusion}

The nanomaterialis an interesting research domain and the most active journals related to this research domain are Construction and Building Materials and Composites Science[3], [10], [11] and Technology. The most activecountrieswere China andthe United States of America.The leading organizations engaged in the research regarding Nanomaterialwerethe Chinese Academy of Sciences, North Eastern University of China, and the Ministry of Education of China.The most active authors who had made valuable contributions related to Nanomaterialwere Wang Y. and Yang H. This research domain offers a new avenue for researchers and the future research can be on Nanomaterial and disease control, and developing chemical control.

\section{References}

A. K. M. Batoo et al., "Structural, morphological and electrical properties of $\mathrm{Cd} 2+$ doped $\mathrm{MgFe} 2-\mathrm{xO} 4$ ferrite nanoparticles," J. Alloys Compd., vol. 726, pp. 179-186, 2017.

B. P. Gairola, S. P. Gairola, V. Kumar, K. Singh, and S. K. Dhawan, "Barium ferrite and graphite integrated with polyaniline as effective shield against electromagnetic interference," Synth. Met., vol. 221, pp. 326-331, 2016.

C. K. Kerman, M. Saito, E. Tamiya, S. Yamamura, and Y. Takamura, "Nanomaterial-based electrochemical biosensors for medical applications," TrAC - Trends Anal. Chem., vol. 27, no. 7, pp. 585-592, 2008.

D. V. B. Sutariya and Y. Pathak, Biointeractions of nanomaterials. CRC Press, 2014.

E. M. Salahinejad, "Nano-QSPR modelling of carbon-based nanomaterials properties," Curr. Top. Med. Chem., vol. 15, no. 18, pp. 1868-1886, 2015.

F. S. Kumar, M. Kumar, and A. Handa, "Combating hot corrosion of boiler tubes - A study," Eng. Fail. Anal., vol. 94, pp. 379-395, Dec. 2018.

G. A. Modak and A. Bhaumik, "Surface-exposed Pd nanoparticles supported over nanoporous carbon hollow 
tubes as an efficient heterogeneous catalyst for the C[sbnd $] \mathrm{C}$ bond formation and hydrogenation reactions," $J$. Mol. Catal. A Chem., vol. 425, pp. 147-156, 2016.

H. P. Keshavarzian and K. Navi, "Optimum quaternary galois field circuit design through carbon nano tube technology," in Proceedings of the 15th International Conference on Advanced Computing and Communications, ADCOM 2007, 2007, pp. 214-219.

I. L. Pan, M. Xu, and Z. D. Zhang, "Synthesis and Electrocatalytic Properties of Co3O4 Nanocrystallites with Various Morphologies," J. Clust. Sci., vol. 21, no. 4, pp. 655-667, 2010.

J. F. Rahmat, N. Thamwattana, and J. M. Hill, "Carbon nanotube oscillators for applications as nanothermometers," J. Phys. A Math. Theor., vol. 43, no. 40, 2010.

K. J.-S. Park and D.-W. Park, "Synthesis of zinc oxide nano-particles using carbon dioxide by DC plasma jet," Surf. Coatings Technol., vol. 205, no. SUPPL. 1, pp. S79-S83, 2010.

L. K. M. Batoo et al., "Structural, morphological and electrical properties of Cd2+doped MgFe2-xO4 ferrite nanoparticles," J. Alloys Compd., vol. 726, pp. 179-186, 2017.

M. P. Gairola, S. P. Gairola, V. Kumar, K. Singh, and S. K. Dhawan, "Barium ferrite and graphite integrated with polyaniline as effective shield against electromagnetic interference," Synth. Met., vol. 221, pp. 326-331, 2016.

N. K. Kerman, M. Saito, E. Tamiya, S. Yamamura, and Y. Takamura, "Nanomaterial-based electrochemical biosensors for medical applications," TrAC - Trends Anal. Chem., vol. 27, no. 7, pp. 585-592, 2008.

O. V. B. Sutariya and Y. Pathak, Biointeractions of nanomaterials. CRC Press, 2014.

P. M. Salahinejad, "Nano-QSPR modelling of carbon-based nanomaterials properties," Curr. Top. Med. Chem., vol. 15, no. 18, pp. 1868-1886, 2015.

Q. S. Kumar, M. Kumar, and A. Handa, "Combating hot corrosion of boiler tubes - A study," Eng. Fail. Anal., vol. 94, pp. 379-395, Dec. 2018.

R. A. Modak and A. Bhaumik, "Surface-exposed Pd nanoparticles supported over nanoporous carbon hollow tubes as an efficient heterogeneous catalyst for the C[sbnd]C bond formation and hydrogenation reactions," $J$. Mol. Catal. A Chem., vol. 425, pp. 147-156, 2016.

S. P. Keshavarzian and K. Navi, "Optimum quaternary galois field circuit design through carbon nano tube technology," in Proceedings of the 15th International Conference on Advanced Computing and Communications, ADCOM 2007, 2007, pp. 214-219.

T. L. Pan, M. Xu, and Z. D. Zhang, "Synthesis and Electrocatalytic Properties of Co3O4 Nanocrystallites with Various Morphologies," J. Clust. Sci., vol. 21, no. 4, pp. 655-667, 2010.

U. F. Rahmat, N. Thamwattana, and J. M. Hill, "Carbon nanotube oscillators for applications as nanothermometers," J. Phys. A Math. Theor., vol. 43, no. 40, 2010.

V. J.-S. Park and D.-W. Park, "Synthesis of zinc oxide nano-particles using carbon dioxide by DC plasma jet," Surf. Coatings Technol., vol. 205, no. SUPPL. 1, pp. S79-S83, 2010.

Web 